\title{
Synthesis of Triphenyltin (IV) and Dibutyltin (IV) Complexes of 1-Aryl-2,5-dithiohydrazodicarbonamides and Their Characterization
}

\author{
Rashmi B. Rastogi, Karuna Singh, and Vinay Jaiswal \\ Department of Chemistry, Indian Institute of Technology (Banaras Hindu University), Varanasi 221005, India
}

Correspondence should be addressed to Rashmi B. Rastogi; rashmi.apc@iitbhu.ac.in

Received 28 October 2013; Accepted 3 February 2014; Published 5 March 2014

Academic Editor: Guennadi E. Zaikov

Copyright (C) 2014 Rashmi B. Rastogi et al. This is an open access article distributed under the Creative Commons Attribution License, which permits unrestricted use, distribution, and reproduction in any medium, provided the original work is properly cited.

Organotin complexes of the types $\mathrm{Ph}_{3} \mathrm{SnL}$ and $\mathrm{Bu}_{2} \mathrm{SnL}$ [where $\mathrm{Ph}=$ phenyl and $\mathrm{Bu}=$ butyl; $\mathrm{HL}=1$-phenyl-2,5-dithiohydrazodicarbonamide (HPhthc), 1-benzyl-2,5-dithiohydrazodicarbonamide (Hbzthc), 1-(4-ethoxyphenyl)-2,5-dithiohydrazodicarbonamide (HEtOPhthc)] have been prepared. Molar conductance studies demonstrate the nonionic behavior of the complexes. The ${ }^{1} \mathrm{H}$ and ${ }^{13} \mathrm{C}$ nuclear magnetic resonance and FAB mass spectra of the complexes are consistent with the proposed stoichiometry. Infrared spectra suggest an anionic bidentate coordinating behavior of the ligands.

\section{Introduction}

Dithiohydrazodicarbonamides have proved to be compounds of versatile behavior. This particular ligand system and its $3 \mathrm{~d}$ metal complexes have been shown to possess high antimicrobial activity $[1,2]$. Anticorrosion properties of these ligands have also been recognized for the corrosion of copper in aqueous chloride solutions [3]. Some 1-aryl-2,5-dithiohydrazodicarbonamides and their molybdenum and tungsten complexes have been found to act as excellent extreme-pressure lubrication additives [4] and corrosion inhibitors for mild steel in $1.0 \mathrm{~N}$ sulfuric acid [5]. Biocidal activity of organotins is well recognized [68]. These have been enormously used as antifouling paints $[9,10]$. Organotins derived from carboxylic acid, phosphoric group, N, S donating groups have been studied as corrosion inhibitors [11-22]. Organotins are known for their friction and wear reducing properties [23-25]. Organotin derivatives of alkylphenols have been successfully used as antiwear additives for lubricating oils [26]. Since organotins and dithiohydrazodicarbonamides both are well known for their biocidal behavior, friction and wear reducing properties and anticorrosive properties, synthesis of organotin complexes with dithiohydrazodicarbonamides was undertaken with intent to explore their applicability as corrosion inhibitors. The present communication, therefore, describes the synthesis of some triphenyltin and dibutyltin dithiohydrazodicarbonamides and their characterization by infrared, proton, and ${ }^{13} \mathrm{C}$ nuclear magnetic resonance spectroscopy and FAB mass spectrometry.

\section{Experimental}

2.1. Materials. Analytical grade reagents were used in the present investigation. The ligands were prepared by refluxing thiosemicarbazide with appropriate aryl isothiocyanates in 50\% ethanol using previously reported methods [27]. In a representative experiment 1-phenyl-2,5dithiohydrazodicarbonamide was synthesized as given below.

Thiosemicarbazide $(0.05 \mathrm{moL})$ and phenyl isothiocyanate $(0.05 \mathrm{moL})$ were mixed with $50 \mathrm{~mL}$ of $50 \%$ ethanol and the mixture was refluxed for one hour. The solid that appeared was filtered, washed with water, and crystallized from ethanol, m.pt. $174^{\circ} \mathrm{C}$.

The structures of dithiohydrazodicarbonamides used for preparation of complexes are given in Figure 1. 


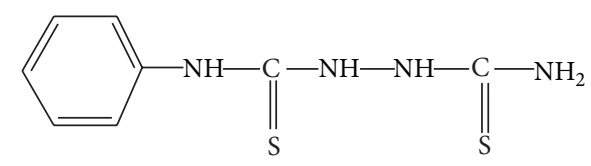

1-Phenyl-2,5-dithiohydrazodicarbonamide (HPhthc)

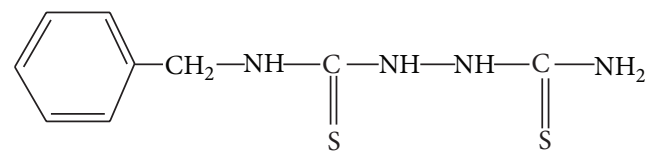

1-Benzyl-2,5-dithiohydrazodicarbonamide (HBzthc)

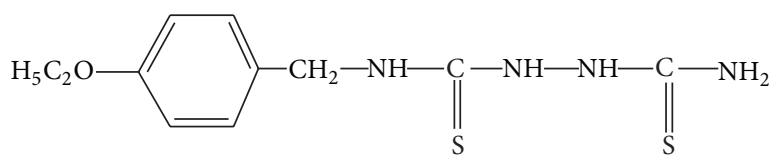

1-(4-Ethoxyphenyl)-2,5-dithiohydrazodicarbonamide (HEtOPhthc)

FIGURE 1: Structures and acronyms of the various dithiohydrazodicarbonamides.

\subsection{Preparation of the Complexes}

2.2.1. Triphenyltin Complexes. To an ethanolic solution of triphenyltin chloride $(3.8 \mathrm{~g}, 10 \mathrm{mmoL})$, an ethanolic solution of the corresponding ligand $(10 \mathrm{mmoL})$ was added with constant stirring. The reaction mixture was stirred at solvent reflux for $4 \mathrm{hrs}$ and excess solvent was removed by distillation at reduced pressure. On addition of excess of petroleum ether to the residual liquid, a dirty-white solid precipitated. The solvent was removed by evaporation and the residual solid was dried at reduced pressure. It was then recrystallized from acetone.

2.2.2. Dibutyltin Complexes. Dibutyltin complexes were synthesized by adding dropwise an ethanolic solution of dibutyltin dichloride $(3.04 \mathrm{~g}, 10 \mathrm{mmoL})$ to a stirred ethanolic solution of the corresponding ligand $(20 \mathrm{mmoL})$. The reaction mixture was stirred at solvent reflux for $3 \mathrm{hrs}$ and the excess solvent was removed by distillation at reduced pressure. The residual liquid was allowed to cool to room temperature. Upon the addition of excess petroleum ether (b.p. $60-80^{\circ} \mathrm{C}$ ), a solid product formed. The solid was collected by filtration, washed with ethanol, and dried at reduced pressure. It was then recrystallized from acetone.

\section{Instrumentation}

Electrical conductance of $10^{-3} \mathrm{M}$ solutions of the complexes in DMSO was measured at room temperature using an inversion-type special conductivity cell with a bright platinum electrode (WTW model LBR/B). Infrared spectra were obtained using a Perkin Elmer 983 spectrophotometer. ${ }^{1} \mathrm{H}$ and ${ }^{13} \mathrm{C}$ NMR spectra were recorded using a Jeol FX Fourier Transform Multinuclear NMR spectrometer and solutions in DMSO- $\mathrm{d}_{6}$ using tetramethylsilane as internal reference.
FAB mass spectra were recorded using a Jeol SX 6000 mass spectrometer and xenon/6 KV/10 $\mathrm{mA}$ as the $\mathrm{FAB}$ gas and NBA $m$-nitrobenzyl alcohol as matrix. Powder X-ray diffraction (XRD) data of the complexes were recorded at room temperature using a Rigaku Cu-rotating anode (Japan) $\mathrm{X}$-ray diffractometer operating at $40 \mathrm{KV}$ and $100 \mathrm{~mA}$ at $1.5406 \AA$ wavelength ( $\mathrm{Cu}-\mathrm{K} \alpha_{1}$ radiation).

\section{Result and Discussion}

The complexes were analyzed for their tin, sulfur, hydrogen, carbon, and nitrogen contents. Tin and sulfur were determined gravimetrically as $\mathrm{SnO}_{2}$ and $\mathrm{BaSO}_{4}$, respectively [28]. Carbon, hydrogen, and nitrogen were determined microanalytically. The analytical data together with molar conductance values are given in Table 1 . As indicated by analytical data, the complexes of the types $\mathrm{Ph}_{3} \mathrm{SnL}$ and $\mathrm{Bu}_{2} \mathrm{SnL}_{2}$ where $[\mathrm{LH}=$ HPhthc, Hbzthc, HEtOPhthc] are formed. All the complexes are soluble in common organic solvents. The molar conductance values of all the complexes are in the range $9-15.5 \mathrm{ohm}^{-1} \mathrm{moL}^{-1} \mathrm{~cm}^{2}$ which shows them to be nonionic [29].

4.1. Infrared Spectra. Prominent IR spectral bands and the corresponding assignments are displayed in Table 2. The IR spectrum of the ligand 1-phenyl-2,5dithiohydrazodicarbonamide (HPhthc) exhibits four bands at $3420,3390,3210$, and $3150 \mathrm{~cm}^{-1}$ which are assigned to $\nu(\mathrm{N}-$ $\mathrm{H}), v\left(\mathrm{NH}_{2}\right), v(\mathrm{NH})\left(\mathrm{ArNH}_{2}\right)$ and $v(\mathrm{~N}-\mathrm{H})(-\mathrm{NH}-\mathrm{NH}-)$, respectively [1]. These bands appear at 3400, 3380, 3220, and $3140 \mathrm{~cm}^{-1}$, respectively, in HEtOPhthc and at 3410, 3370, 3250 , and $3180 \mathrm{~cm}^{-1}$, respectively, in Hbzthc. The position of the first two bands is almost unaffected by complexation indicating that the primary amino $\left(-\mathrm{NH}_{2}\right)$ nitrogen is not involved in the coordination. Upon complexation, the third band of the ligands becomes broad and the fourth band is absent suggesting that at least one of the $>\mathrm{NH}$ groups is involved in coordination and formation of the complexes. The $\beta\left(\mathrm{NH}_{2}\right)$ and $\nu(\mathrm{N}-\mathrm{N})$ absorption bands of strong intensity in the spectra of the ligand appearing at 16001640 and $980 \mathrm{~cm}^{-1}$, respectively, show lower and higher energy shifts of $10-20$ and $20-40 \mathrm{~cm}^{-1}$, respectively, on complexation indicating that one of the hydrazinic nitrogen atoms is involved in coordination [1]. The thioamide band I $[\beta(\mathrm{NH})+\nu(\mathrm{CN})]$ and thioamide band II $[\nu(\mathrm{CN})+$ $\beta(\mathrm{NH})]$ appearing for the ligands at approximately 1500 and $1300 \mathrm{~cm}^{-1}$, respectively, undergo shifts of higher energy 20 $90 \mathrm{~cm}^{-1}$ upon complexation due to the reduction of the $>C=S$ bond order from two to one and an increase in the $>\mathrm{C}-\mathrm{N}$ bond order from one to two as a result of thioenolisation.

The position of absorption for the thioamide IV bands appearing at $880-840 \mathrm{~cm}^{-1}$ in the ligands remains almost unchanged in the spectra of the complexes and a new band around $810-770 \mathrm{~cm}^{-1}$ due to the $\nu(\mathrm{C}-\mathrm{S})$ stretching vibration is present, suggesting that one of the $>\mathrm{C}=\mathrm{S}$ groups is not involved in the coordination. The appearance of a new band in the region $810-770 \mathrm{~cm}^{-1}$ in the spectra of the complexes 
TABLE 1: Analytical data and behavior of organotin (IV) dithiohydrazodicarbonamide complexes.

\begin{tabular}{|c|c|c|c|c|c|c|c|}
\hline \multirow{2}{*}{$\begin{array}{l}\text { Complex empirical } \\
\text { formula }\end{array}$} & \multirow{2}{*}{ Color } & \multicolumn{2}{|c|}{ Anal. \% } & \multicolumn{3}{|c|}{ Found (calculated) } & \multirow{2}{*}{$\begin{array}{l}\text { Molar conductance } 10^{-3} \mathrm{M} \text { in } \\
\text { DMSO }\left(\mathrm{ohm}^{-1} \mathrm{~mol}^{-1} \mathrm{~cm}^{2}\right)\end{array}$} \\
\hline & & $\mathrm{C}$ & $\mathrm{H}$ & $\mathrm{N}$ & S & $\mathrm{Sn}$ & \\
\hline $\begin{array}{l}\mathrm{Ph}_{3} \mathrm{Sn}(\mathrm{Phthc}) \\
\mathrm{C}_{26} \mathrm{H}_{24} \mathrm{~N}_{4} \mathrm{~S}_{2} \mathrm{Sn}\end{array}$ & $\begin{array}{l}\text { Pale } \\
\text { white }\end{array}$ & $54.73(54.35)$ & $4.21(4.18)$ & $9.82(9.75)$ & $11.22(11.14)$ & $20.70(20.55)$ & 10.90 \\
\hline $\begin{array}{l}\mathrm{Bu}_{2} \mathrm{Sn}(\mathrm{Phthc})_{2} \\
\mathrm{C}_{24} \mathrm{H}_{36} \mathrm{~N}_{8} \mathrm{~S}_{4} \mathrm{Sn}\end{array}$ & $\begin{array}{l}\text { Pinkish } \\
\text { white }\end{array}$ & $42.35(42.22)$ & $5.29(5.27)$ & $16.47(16.42)$ & $18.82(18.76)$ & 17.35 (17.30) & 15.50 \\
\hline $\begin{array}{l}\mathrm{Ph}_{3} \mathrm{Sn}(\text { Bzthc }) \\
\mathrm{C}_{27} \mathrm{H}_{26} \mathrm{~N}_{4} \mathrm{~S}_{2} \mathrm{Sn}\end{array}$ & White & $55.91(55.10)$ & $4.40(4.42)$ & $9.49(9.52)$ & $10.84(10.88)$ & $20.01(20.06)$ & 9.63 \\
\hline $\begin{array}{l}\mathrm{Bu}_{2} \mathrm{Sn}(\mathrm{Bzthc}){ }_{2} \mathrm{Et} \\
\mathrm{C}_{26} \mathrm{H}_{40} \mathrm{~N}_{8} \mathrm{~S}_{4} \mathrm{Sn}\end{array}$ & $\begin{array}{l}\text { Dirty } \\
\text { white }\end{array}$ & $44.08(43.94)$ & $5.64(5.63)$ & $15.81(15.77)$ & $18.07(18.02)$ & $16.66(16.61)$ & 14.70 \\
\hline $\begin{array}{l}\mathrm{Ph}_{3} \mathrm{Sn} \text { (EtOPhthc) } \\
\mathrm{C}_{28} \mathrm{H}_{28} \mathrm{~N}_{4} \mathrm{OS}_{2} \mathrm{Sn}\end{array}$ & Cream & $54.45(54.19)$ & $4.86(4.83)$ & $9.07(9.03)$ & $10.37(10.32)$ & $19.12(19.03)$ & 6.15 \\
\hline $\begin{array}{l}\mathrm{Bu}_{2} \mathrm{Sn}(\text { EtOPhthc })_{2} \\
\mathrm{C}_{28} \mathrm{H}_{44} \mathrm{~N}_{8} \mathrm{O}_{2} \mathrm{~S}_{4} \mathrm{Sn}\end{array}$ & White & $43.86(43.63)$ & $5.74(5.71)$ & $14.62(14.54)$ & $16.71(16.62)$ & $15.40(13.32)$ & 9.61 \\
\hline
\end{tabular}

TABLE 2: IR spectral bands $\left(\mathrm{cm}^{-1}\right)$ and their assignments.

\begin{tabular}{|c|c|c|c|c|c|c|c|c|c|c|}
\hline Complex & $v(\mathrm{~N}-\mathrm{H})$ & $v\left(\mathrm{NH}_{2}\right)$ & $\begin{array}{c}{[\beta(\mathrm{N}-\mathrm{H})+v} \\
(\mathrm{CN})] \\
\text { Thiomide I }\end{array}$ & $\begin{array}{c}{[\nu(\mathrm{CN})+\beta} \\
(\mathrm{N}-\mathrm{H})] \\
\text { Thiomide II }\end{array}$ & $\begin{array}{c}[\nu(\mathrm{C}=\mathrm{S}) / \mathrm{C}-\mathrm{S})] \\
\text { Thiomide IV }\end{array}$ & $\beta\left(\mathrm{NH}_{2}\right)$ & $v(\mathrm{Sn}-\mathrm{C})$ & $v(\mathrm{Sn}-\mathrm{S})$ & $\nu(\mathrm{Sn}-\mathrm{N})$ & $v(\mathrm{~N}-\mathrm{N})$ \\
\hline HPhthc & $\begin{array}{l}3420 \\
3390\end{array}$ & $\begin{array}{l}3210 \\
3150\end{array}$ & 1500 & 1300 & 840 & 1640 & - & - & - & 980 \\
\hline $\mathrm{Ph}_{3} \mathrm{Sn}(\mathrm{Phthc})$ & $\begin{array}{l}3410 \\
3380\end{array}$ & $\begin{array}{l}3200 \\
3150\end{array}$ & 1555 & 1385 & 770 & 1650 & 600 & 384 & 354 & 1005 \\
\hline $\mathrm{Bu}_{2} \mathrm{Sn}((\mathrm{Phthc}))_{2}$ & $\begin{array}{l}3400 \\
3364\end{array}$ & $\begin{array}{l}3180 \\
3140\end{array}$ & 1560 & 1390 & 760 & 1645 & 590 & 370 & 360 & 1010 \\
\hline HEtOPhthc & $\begin{array}{l}3400 \\
3380\end{array}$ & $\begin{array}{l}3220 \\
3140\end{array}$ & 1520 & 1300 & 810 & 1610 & - & - & - & 960 \\
\hline $\mathrm{Ph}_{3} \mathrm{Sn}$ (EtOPhthc) & $\begin{array}{l}3390 \\
3370\end{array}$ & $\begin{array}{l}3210 \\
3120\end{array}$ & 1570 & 1365 & 720 & 1605 & 585 & 380 & 340 & 980 \\
\hline $\mathrm{Bu}_{2} \mathrm{Sn}(\mathrm{EtOPhthc})_{2}$ & $\begin{array}{l}3400 \\
3360\end{array}$ & $\begin{array}{r}3220 \\
3110\end{array}$ & 1580 & 1360 & 710 & 1610 & 610 & 397 & 350 & 985 \\
\hline HBzthc & $\begin{array}{l}3410 \\
3370\end{array}$ & $\begin{array}{l}3250 \\
3180\end{array}$ & 1510 & 1320 & 880 & 1600 & - & - & - & 900 \\
\hline $\mathrm{Ph}_{3} \mathrm{Sn}($ Bzthc $)$ & $\begin{array}{l}3400 \\
3365\end{array}$ & $\begin{array}{l}3240 \\
3160\end{array}$ & 1535 & 1380 & 805 & 1590 & 617 & 390 & 310 & 940 \\
\hline $\mathrm{Bu}_{2} \mathrm{Sn}(\mathrm{Bzthc})_{2}$ & $\begin{array}{l}3400 \\
3360\end{array}$ & $\begin{array}{l}3250 \\
3150\end{array}$ & 1540 & 1370 & 810 & 1580 & 605 & 380 & 315 & 950 \\
\hline
\end{tabular}

indicates that coordination of the metal through the "thiolo" sulfur has occurred.

New bands appearing in the far-IR spectra of all the complexes in the region 580-620, 310-360, and 370-390 $\mathrm{cm}^{-1}$ may be tentatively assigned to $v(\mathrm{Sn}-\mathrm{C}), \nu(\mathrm{Sn}-\mathrm{N})$, and $\nu(\mathrm{Sn}-$ S) modes, respectively [28].

4.2. ${ }^{1} \mathrm{H}$ NMR Spectra. ${ }^{1} \mathrm{H}$ NMR spectrum of the ligand HPhthc recorded in DMSO- $\mathrm{d}_{6}$ exhibits $\mathrm{D}_{2} \mathrm{O}$ exchangeable resonance signals at $\delta 9.93(-\mathrm{NH}-\mathrm{NH})$ and $\delta 2.36(\mathrm{~s},-$ $\mathrm{NH}_{2}$ ) ppm. Aromatic protons, together with the $-\mathrm{NH}$ proton, are observed as a multiplet between $\delta 7.74$ and $7.06 \mathrm{ppm}$. However, the complexes of the ligand HPhthc show a $\mathrm{NH}-\mathrm{NH}$ proton signal at $\delta 9.70 \mathrm{ppm}$ due to one proton only, supporting the view that one proton has undergone deprotonation after thioenolisation to form the complex. Other proton signals of the ligand appear at more deshielded positions in the complexes. The electronic environment around these protons has changed to some extent as a consequence of complexation.

4.3. ${ }^{13} \mathrm{C} N M R$ Spectra. The ${ }^{13} \mathrm{C}$ NMR spectrum of HBzthc displays resonance signals between $\delta 120.0$ and $131.8 \mathrm{ppm}$ corresponding to the carbon atoms of the benzyl group and a single peak at $\delta 170.6$ and $\delta 171.3 \mathrm{ppm}$ due to $>\mathrm{C}=\mathrm{S}$ carbon atoms. The spectra of $\mathrm{Ph}_{3} \mathrm{SnPhthc}$ and $\mathrm{Bu}_{2} \mathrm{Sn}$ (Phthc) indicate greater deshielding of the $>\mathrm{C}=\mathrm{S}$ carbon as compared to the ligand which may arise due to the presence of $-\mathrm{N}=\mathrm{C}-\mathrm{S}$ from $-\mathrm{HN}-\mathrm{C}=\mathrm{S}$ after the removal of proton upon thioenolisation.

4.4. FAB Mass Spectra. The FAB mass spectrum of $\mathrm{Ph}_{3} \mathrm{SnPhthc}$ shows several peaks due to various fragments resulting from its ionization. The presence of a prominent 


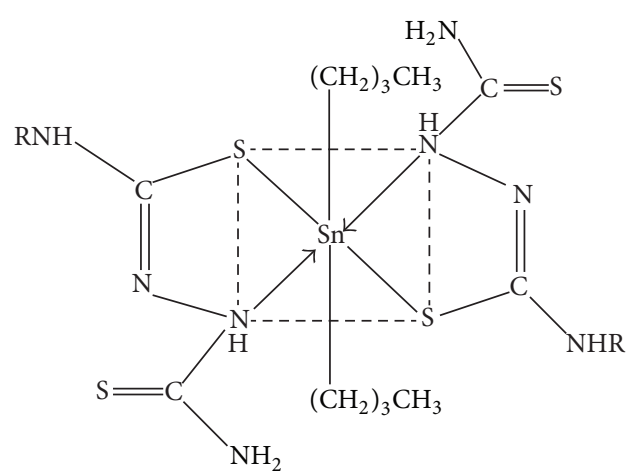

Dibutyltin bis(1-aryl-2,5-dithiohydrazodicarbonamide)

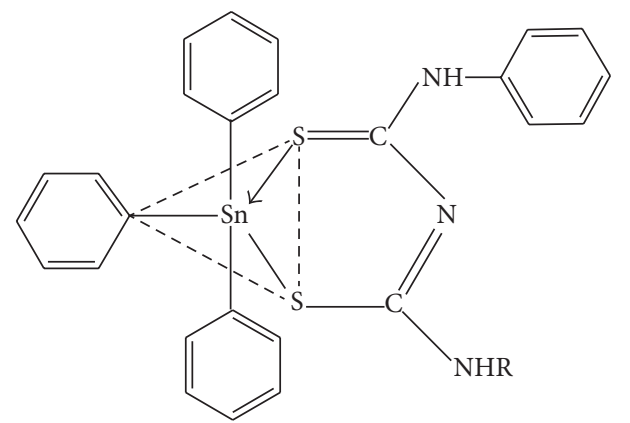

Triphenyltin 1-aryl-2,5-dithiohydrazodicarbonamide

Where $\mathrm{R}=$

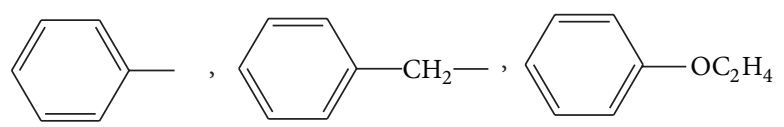

Figure 2: Proposed structure of organotin (IV) complexes.

peak at $m / z=226$ for the ligand HPhthc and an intense molecular ion peak at $m / z=570\left(-4 \mathrm{H}^{+}\right)$, (59) reflects its monomeric nature. The spectrum of $\mathrm{Bu}_{2} \mathrm{Sn}(\mathrm{EtOPhthc})_{2}$ contains a low intensity peak at $m / z=766\left(-4 \mathrm{H}^{+}\right)$, (11) which corresponds to the molecular ion peak of complex.

Based on analytical data and the physicochemical studies noted, structures for the proposed complexes have been proposed. These structures are shown in Figure 2.

\section{Conflict of Interests}

The authors declare that there is no conflict of interests regarding the publication of this paper.

\section{Acknowledgments}

The financial assistance from All India Council of Technical Education, New Delhi, is gratefully acknowledged. The authors are thankful to Head, Department of Chemistry, Faculty of Science, Banaras Hindu University, for providing IR and NMR facilities.

\section{References}

[1] S. Prasad, A. Bhattacharya, V. K. Verma, S. Jayanti, and D. C. Rupainwar, "Synthetic and biocidal studies on the complexes of 1-aryl-2,5-dithiohydrazodicarbonamide with $\mathrm{Co}(\mathrm{II}), \mathrm{Cu}(\mathrm{II})$, and Zn(II)," Synthesis and Reactivity in Inorganic and MetalOrganic Chemistry, vol. 22, no. 5, pp. 489-507, 1992.

[2] K. S. Prasad, L. S. Kumar, M. Prasad, and H. D. Revanasiddappa, "Novel organotin(IV)-Schiff base complexes: synthesis, characterization, antimicrobial activity, and DNA interaction studies," Bioinorganic Chemistry and Applications, vol. 2010, Article ID 854514, 9 pages, 2010.

[3] M. M. Singh, R. B. Rastogi, B. N. Upadhyay, and M. Yadav, "Thiosemicarbazide, phenyl isothiocyanate and their condensation product as corrosion inhibitors of copper in aqueous chloride solutions," Materials Chemistry and Physics, vol. 80, no. 1, pp. 283-293, 2003.

[4] R. B. Rastogi, M. Yadav, and A. Bhattacharya, "Application of molybdenum complexes of 1-aryl-2,5-dithiohydrazodicarbonamides as extreme pressure lubricant additives," Wear, vol. 252, no. 9-10, pp. 686-692, 2002.

[5] R. B. Rastogi, M. M. Singh, and M. Yadav, "Inhibition of corrosion of mild steel by 1-aryl-2,5-dithiohydrazodicarbonamides and their molybdenum and tungsten complexes in $0.1 \mathrm{~N}$ sulphuric acid," Bulletin of Electrochemistry, vol. 20, pp. 19-24, 2004.

[6] A. Bacchi, M. Carcell, and P. Petagatti, "Antimicrobial and mutagenic properties of organotin(IV) complexes with isatin and $\mathrm{N}$-alkylisatin bisthiocarbonohydrazones," Journal of Inorganic Biochemistry, vol. 99, no. 2, pp. 397-408, 2005.

[7] C. Pellerito, L. Nagy, L. Pellerito, and A. Szorcsik, "Biological activity studies on organotin(IV)n+ complexes and parent compounds," Journal of Organometallic Chemistry, vol. 691, no. 8, pp. 1733-1747, 2006.

[8] Z. U. Rehman, N. Muhammad, and S. Schuja, "New dimeric, trimeric and supramolecular organotin(IV) dithiocarboxylates: synthesis, structural characterization and biocidal activities," Polyhedron, vol. 28, no. 16, pp. 3439-3448, 2009.

[9] O. S. Ayanda, O. S. Fatoki, F. A. Adekola, and B. J. Ximba, "Fate and remediation of organotin compounds in seawaters and soils," Chemical Science Transactions, vol. 1, no. 3, pp. 470481, 2012.

[10] S. Sadiq-ur-Rehman, S. Ali, S. Shahzadi, A. Malik, and E. Ahmed, "Synthesis, characterization, and biocidal studies of the newly synthesized di- and triorganotin(IV) complexes with nbutylhydrogen phthalate," Turkish Journal of Chemistry, vol. 31, no. 3, pp. 371-387, 2007.

[11] R. N. Singh and V. B. Singh, "Corrosion behavior and inhibitive effects of organotin compounds on nickel in formic acid," Corrosion, vol. 49, no. 7, pp. 569-575, 1993.

[12] R. N. Singh and V. B. Singh, "Organo-tin compounds as corrosion inhibitor for nickel in acetic acid solution," Materials Transactions-The Japan Institute of Metals, vol. 38, pp. 49-53, 1997.

[13] A. K. Sawyer, Organotin Compounds, vol. 3, Marcel Dekker, New York, NY, USA, 1971.

[14] R. B. Rastogi, M. M. Singh, K. Singh, and M. Yadav, "Organotin dithiobiurets as corrosion inhibitors for mild steel-dimethyl sulfoxide containing HCl," African Journal of Pure and Applied Chemistry, vol. 5, no. 2, pp. 19-33, 2011.

[15] R. B. Rastogi, M. M. Singh, K. Singh, and J. L. Maurya, "Electrochemical behavior of mild steel in dimethyl sulfoxide 
containing hydrochloric acid," Portugaliae Electrochimica Acta, vol. 28, no. 6, pp. 359-371, 2010.

[16] R. B. Rastogi, M. N. Singh, K. Singh, and J. L. Maurya, "Studies on corrosion inhibiting properties of organotin thiobiurets for mild steel dimethyl sulphoxide containing $\mathrm{HCl}$," Bulletin of Electrochemistry, vol. 22, no. 8-9, pp. 355-361, 2006.

[17] R. B. Rastogi, M. M. Singh, K. Singh, and M. Yadav, "Organotin dithiohydrazodicarbonamides as corrosion inhibitors for mild steel-dimethyl sulphoxide containing HCl," Portugaliae Electrochimica Acta, vol. 22, no. 2, pp. 315-332, 2005.

[18] V. K. Jain, "The chemistry and applications of organotin(IV) complexes of phosphorus-based acids," Coordination Chemistry Reviews, vol. 135-136, pp. 809-843, 1994.

[19] R. B. Rastogi and M. Yadav, "Synthesis of some molybdenum(V) and tungsten(V) complexes of 1-aryl-2,5-dithiohydrazodicarbonamides," Journal of the Indian Chemical Society, vol. 82, pp. 448-451, 2005.

[20] R. B. Rastogi, K. Singh, and J. L. Maurya, "Synthesis and characterization of organotin(IV) thiobiurets," Synthesis and Reactivity in Inorganic, Metal-Organic, and Nano-Metal Chemistry, vol. 42, no. 4, pp. 616-620, 2012.

[21] R. B. Rastogi, K. Singh, and J. L. Maurya, "Synthesis and characterization of organotin(IV) dithiobiurets," The IUP Journal of Chemistry, vol. 4, no. 3, pp. 7-19, 2011.

[22] R. Singh, P. Chaudhary, and N. K. Kaushik, "A review: organotin compounds in corrosion inhibition," Reviews in Inorganic Chemistry, vol. 30, no. 4, pp. 275-294, 2010.

[23] Y. Junbin and D. J. Xiu, "Tribocatalysis reaction during antiwear synergism between borates and Sn(IV) compounds in boundary lubrication," Tribology International, vol. 29, no. 5, pp. 429432, 1996.

[24] V. L. Lashkhi, O. N. Tsvetkov, F. N. Ermolov et al., "Organotin derivatives of alkylphenols as antiwear additives for lubricating oils," Khimiya i Tekhnologiya Topliv i Masel, no. 4, pp. 54-57, 1977.

[25] R. D. Liu, D. H. Tao, and S. F. Fu, "A study of the tribological behaviour of an organotin compound," Lubrication Science, vol. 17, no. 4, pp. 419-429, 2006.

[26] Y. Junbin, "The antiwear synergism between an organotin compound and a ZnDDP," Lubrication Science, vol. 14, no. 3, pp. 377-381, 2002.

[27] V. A. I. Vogel, A Textbook of Quantitative Inorganic Analysis, ELBS, Longman, London, UK, 1978.

[28] T. N. Srivastava, V. Kumar, and R. B. Rastogi, "Some diorganotin dithiocarbamates," Journal of Inorganic and Nuclear Chemistry, vol. 40, no. 3, pp. 399-401, 1978.

[29] W. J. Geary, "The use of conductivity measurements in organic solvents for the characterisation of coordination compounds," Coordination Chemistry Reviews, vol. 7, no. 1, pp. 81-122, 1971. 

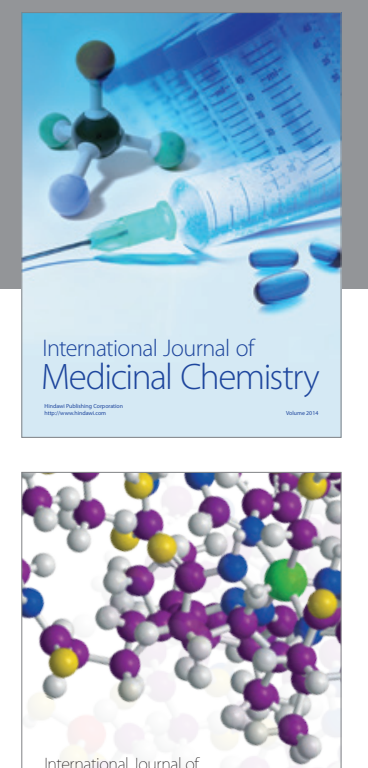

\section{Carbohydrate} Chemistry

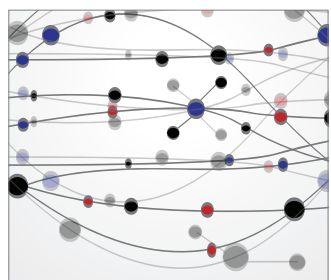

The Scientific World Journal
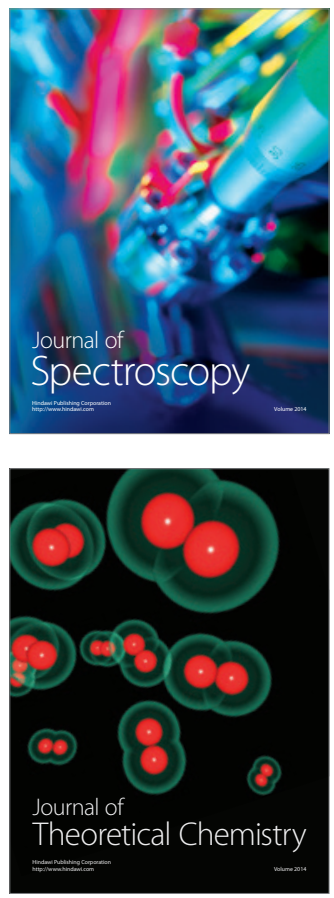
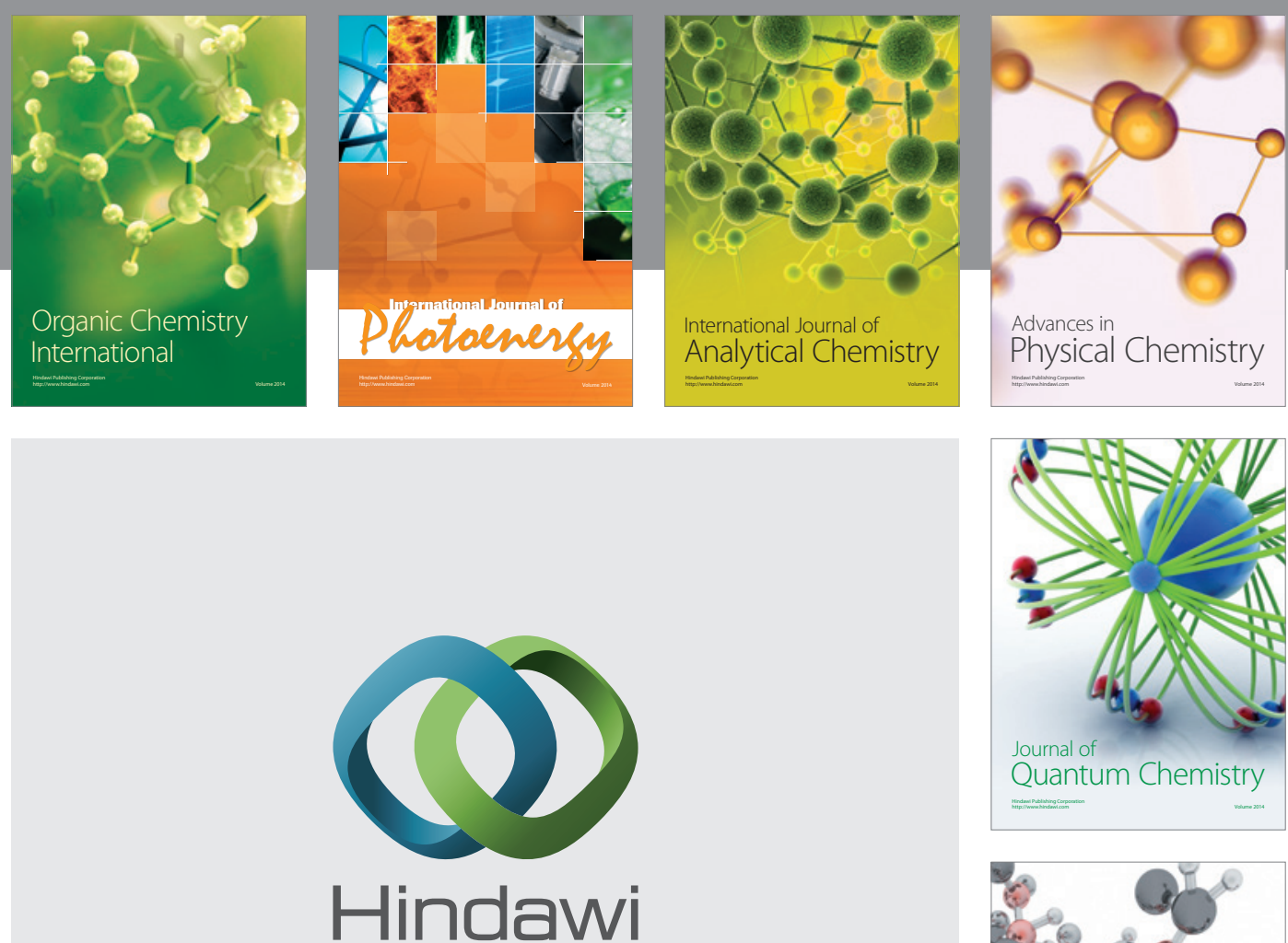

Submit your manuscripts at

http://www.hindawi.com

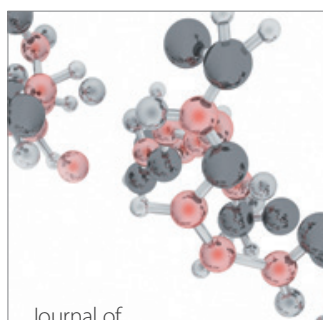

Analytical Methods

in Chemistry

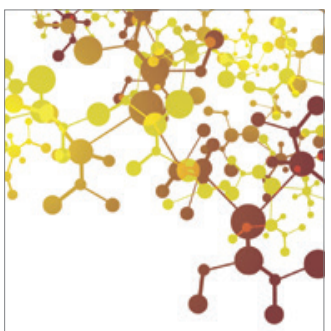

Journal of

Applied Chemistry

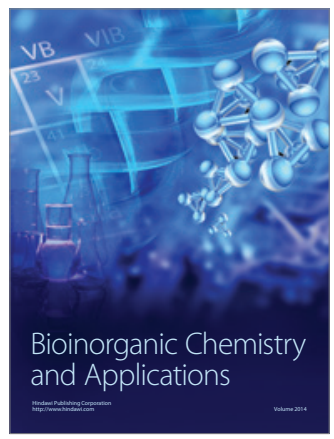

Inorganic Chemistry
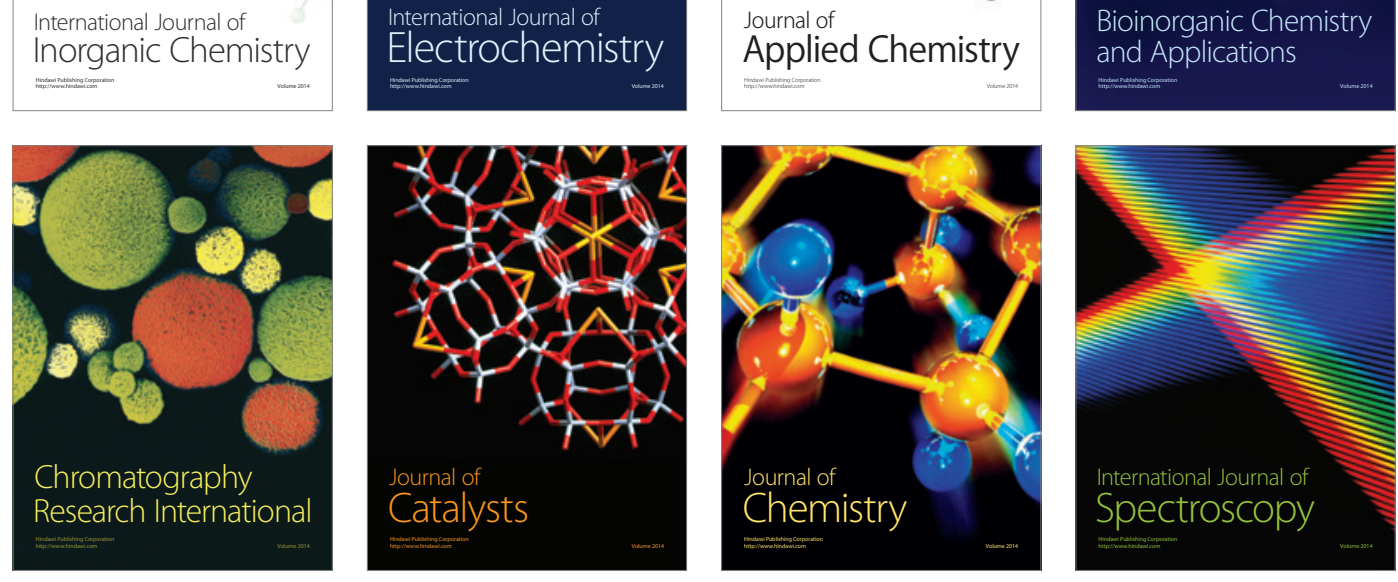